\title{
Effect of mineral injectable supplementation with phosphorus, selenium, magnesium, copper and potassium on follicular growth of Bos taurus or crossbreed beef cows during the protocol of FTAI
}

Gilson Antonio Pessoa ${ }^{[a]}$, Ana Paula Martini ${ }^{[b]}$, Eliana Burtet Parmeggiani ${ }^{[b]}$, Bruno Sivieri de Lima $a^{[c]}$, Giovani Pastre ${ }^{[c]}$, Luc Dure ${ }^{[[]]}$, Gustave Decuadro-Hansen ${ }^{[\mathrm{e}]}$

\author{
[a] Universidade de Caxias do Sul (UCS), Caxias do Sul, RS, SP, Brazil \\ [b] Universidade Federal de Santa Maria (UFSM), Santa Maria, RS, Brazil \\ [c] Virbac do Brasil, São Paulo, SP, Brazil \\ [d] Virbac Global Technical Service, Carros, Alpes-Maritimes, France \\ [e] Virbac América Latina, Buenos Aires, Argentina
}

${ }^{*}$ Corresponding author

e-mail: bruno.lima@virbac.com.br

\section{Abstract}

This study aimed to evaluate the effect of an injectable supplementation in phosphorus, selenium, magnesium, copper and potassium (Fosfosal ${ }^{\circledR}$, Virbac, Brazil) on follicular growth in beef cows subjected to FTAI including two dose regimens of eCG (Novormon ${ }^{\circledR}$, Zoetis, Brazil). Two hundred four (204) Bos taurus (Hereford, Angus, or crossbreed) primiparous cows with their calves, at $45 \pm 15 \mathrm{~d}$ postpartum and BCS average of $2.59 \pm 0.02$ (1-thin, 5-obese) from one farm in the central Rio Grande do Sul, were enrolled in this study. On day 1 cows were subjected to an ultrasound exam (rectal linear transducer 5-10 Mhz, Mindray DP2200, Shenzhen, China) to assess the ovarian activity. Cows were then randomly allocated to four groups 1) F300 $(n=68), 2), F 400(n=52), 3)$ C300 ( $=53), 4)$ C400 ( $=81)$. F groups were supplemented with 2 injections of trace minerals (Fosfosal ${ }^{\circledR}, 10 \mathrm{~mL}$, IM - ITM) on days 0 and 9. FTAI protocol included P4 - impregnated CIDR associated to $2 \mathrm{mg}$ of estradiol benzoate on day 0 . On day 9, the CIDR was removed, and cows were dosed with $12.5 \mathrm{mg}$ dinoprost tromethamine and $1 \mathrm{mg}$ estradiol cypionate. According to groups they were allocated to, cows were also injected with either 300 or 400 UI of eCG. AI were carried out using frozen semen. US were used to evaluate cyclicity (d0), follicular dynamics (d9 and d11), ovulation rate (d14) and Corpus luteum (CL) diameter (d18) and pregnancy at AI (d41). Only 46\% of cows exhibited CL at the d0. 98 females were categorized having low BCS $(\leq 2.5)$, the remaining animals $(n=106)$ having high BCS $(\geq 2.75)$.The dose of eCG and ITM does not influence the follicular diameter (FD) at d9. Cows with BCS $\geq 2.75$ had higher FD at remove of P4 with $9 \mathrm{~d}(10.44 \pm 0.3 \mathrm{~mm})$ compared to $8 \mathrm{~d}(9.66 \pm 0.2 \mathrm{~mm} ; \mathrm{p}<0.01)$. The FD was similar at 
d11 in cows with BCS $\leq 2.5$ or $\geq 2.75$. However, cows that were injected with ITM had significantly greater $(\mathrm{P}<0.05)$ FDs at $\mathrm{AI}$ than cows in control group $(15.42 \pm 0.11 \mathrm{~mm}$ vs $14.62 \pm 0.39 \mathrm{~mm})$. Follicular increase was significantly higher $(\mathrm{P}<0.05)$ in cows that received ITM compared control Group $(4.5 \pm 0.13 \mathrm{~mm}$ vs $4.2 \pm$ $0.08 \mathrm{~mm}$ ). Ovulation rates were similar in animals with ITM and controls (85.6 $\pm 0.04 \%$ and $72.0 \pm 0.04 \%$ ). No difference was observed in CL diameter between ITM dosed animals and controls $(22.5 \pm 0.55 \mathrm{~mm}$ and $22.67 \pm 0.45 \mathrm{~mm}$ ). We conclude that the BCS affects the FD at d9. Additionally two application of Fosfosal ${ }^{\circledR}$ at implementation and removal of CIDR increase the follicular growth between $\mathrm{d} 9$ and $\mathrm{d} 11$. 